\title{
A Correlational Study on the Gross Domestic Product and Gross Domestic Product Per Capita of a Country and Its COVID-19 Incidence and Mortality Rates
}

\author{
Joseph Emmanuel G. Lopez
}

December 21, 2021

\begin{abstract}
Some studies had shown that there is a relationship between the state of the economy of a country and COVID-19 incidence and mortality rates. However, these studies are mostly done on countries that are already developed. This study aims to find the relationship between GDP and GDP per capita and COVID-19 incidence and mortality rates in all countries. In addition, they will also be analyzed based on their different income levels. The data collected are from databases from World Bank and WHO and are analyzed through MS Excel and JASP. Spearman's rho is used to analyze the overall data and stratified data. It has been found that the GDP per capita and incidence $\left(\mathrm{r}_{\mathrm{s}}=.656, \mathrm{p}<.001\right)$ and mortality rates $\left(\mathrm{r}_{\mathrm{s}}=.521, \mathrm{p}<.001\right)$ have a strong and moderate correlation, respectively. GDP's relationship with incidence $\left(\mathrm{r}_{\mathrm{s}}=.295, \mathrm{p}<.001\right)$ and mortality rates $\left(\mathrm{r}_{\mathrm{s}}=.346, \mathrm{p}<.001\right)$ resulted in both weak correlations. Stratified analysis resulted in no significant relationships, except for GDP per capita's relationship with incidence $\left(\mathrm{r}_{\mathrm{s}}=.362, \mathrm{p}=.011\right)$ and mortality rates $\left(\mathrm{r}_{\mathrm{s}}=.348, \mathrm{p}=.014\right)$ in low-middle countries, which yielded both weak correlations. These results show that there is indeed a relationship between the incidence and mortality rates and the economic status of a country before a pandemic, however, more factors need to be accounted for in order to help countries improve their pandemic response in the future.
\end{abstract}




\section{Introduction}

During the COVID-19 pandemic that the world is currently in, differences in the treatment of a person based on one's country of origin are striking. Only $1.9 \%$ of people in low-income countries have received a dose of a COVID-19 vaccine, while $65.55 \%$ of people in high-income countries have received a dose of the vaccine (Our World In Data, 2021). This shows that there are wide disparities in how COVID-19 are taken action by different countries.

However, even before the COVID-19 pandemic, this inequality is already part of the different healthcare systems of the world. A study done on five European Union candidates show that the GDP per capita correlates positively with the life expectancy at birth, as the increase in the development of infrastructures leads to the longevity of life (Miladinov, 2020). This shows that the size of the economy of a country has an effect on the health of the general populace.

This research aims to address this health inequality by looking for a relationship between two economic metrics (Gross Domestic Product or GDP and Gross Domestic Product per Capita or GDP per Capita) and COVID-19 mortality rates. This will shed light on the economic inequalities that the healthcare systems of different countries experiences. Currently, there are no studies that have been done analyzing the effects of these two economic metrics and COVID-19 incidence and mortality rates. There is a study that has been done (König and Winkler, 2021) that analyzed the effects of lockdowns caused by COVID-19 fatalities on GDP growth, however, the sample size is non-representative of the whole world, as the majority of the countries in the research's sample are OECD countries. There is also a study done (Shahbazi and Khazaei, 2020) which correlates HDI (Human Development Index) and COVID-19 incidence and mortality rates. Since HDI has many factors in its calculation (i.e. life expectancy at birth, mean years of schooling, and gross national income, the study focused on socio-economic inequalities, while this study focuses on economic differences solely. Because of this, the following research question will be addressed in this study:

- What is the relationship between the gross domestic product (GDP) and gross domestic product per capita (GDP per Capita) of a country to its incidence and mortality rates of COVID-19?

\section{Literature Review}

\section{The Relationship Between the Economy and Healthcare}

The economy and the healthcare system affect each other in a multitude of ways. A study done has suggested that the healthcare budget should consider a patients' needs and preferences when treating a disease (Ottolini et al., 2016). In addition, the healthcare system must use economics in order to evaluate its social equity. In a healthcare system, these analyses are important in order to maximize its efficiency while maintaining the pre-determined budget for it.

There is also a relationship between infectious diseases, human capital, and economic growth. Researchers in a study had developed an endogenous growth model relating the causes of ill health to the extent of the infectious disease being studied (Goenka and Liu, 2020). This in turn prevents people from working, which decreases human capital. The study also showed that forgotten diseases do not affect mortality in a significant manner, however, they mostly affect the poor, which makes it an indicator of poverty.

Lastly, there is a relationship between socioeconomic development and the life expectancy of a country. In a study done with European accession candidate countries (Miladinov, 2020), the income per capita of a country and the infant mortality rate have significant effects on the life expectancy at birth. The study found that there is an inverse relationship between a country's population health and socioeconomic development with infant mortality, while there is a direct relationship between a country's population health 
and socioeconomic development with life expectancy. However, it is notable that the sample is small, which makes it non-representative for all of the countries in the world.

These examples show that the economy and healthcare are interconnected and have a deep relationship because of the inherent demand for healthcare, especially during the COVID-19 pandemic.

\section{The Economy, Society, and COVID-19}

Research suggests that because of the COVID-19 pandemic, the global gross domestic product (GDP) will fall by $3 \%$ (Mou, 2020). However, the drop is not equal to all countries, with developing countries' GDP dropping by $4 \%$, with some countries having a drop of $>6.5 \%$. Because of this, there is a need for international cooperation in order to prevent the spread of COVID-19, which will help the economy in the long run (Ahmad et al., 2020).

Because of this, many countries had implemented lockdowns and health protocols. One of the rapidly growing economies of the world, India has implemented a 21-day lockdown, with the country experiencing a drop in its GDP growth forecast, from 5.3\% to 2.5\% (Sharma and Mahendru, 2020). In the same study by Sharma and Mahendru, they had suggested that the Indian government to balance the intensity of lockdowns and economic development during the COVID-19 pandemic. They also discussed that economic stimuli are useful in keeping people inside because when people have no food to eat, they will resort to finding jobs outside, which will endanger more lives during the COVID-19 pandemic.

However, economic inequality is not the only inequality that is exacerbated by the pandemic. Gender differences are also intensified, as shown in a study that shows that female caregivers are more likely to contract SARS-CoV-2 because of increased exposure risk (Connor et al., 2020). In drug development trials, some researchers failed to include pregnant people in their studies, which might lead to possible risks not being researched enough. Another point made in the study is the increase in the partner and gender-based violence because of the lockdowns that are in place. Through this, there are multiple factors that cause stress in women, which are exacerbated by COVID-19. The researchers suggest that policies that consider the unique experiences of women must be implemented in order to lessen the inequalities that women experience during the pandemic.

\section{Incidence and Mortality Rates}

Incidence and mortality rates are important in understanding the extent of a pandemic. A beta regression model was developed in a study to understand the epidemiological indicators of morbidity (incidence rate) and mortality (mortality rate by cause and case-fatality rate) (de Oliveira et al., 2020). In another article, researchers identified different health indicators that might correlate with the case fatality rates of COVID-19 (Ergönül et al., 2021). Some factors that are of interest that decrease the case-fatality rate are the COVID-19 test rate, hospital bed density, and the rural population ratio.

Incidence and mortality rates from COVID-19 are also found to be directly proportional to the Human Development Index (Shahbazi and Khazaei, 2020). The Human Development Index or HDI is measured from a 0 to 1 scale, with 1 having a very high human development and 0 having a low human development (United Nations Development Programme, 2020) It is interesting to note that countries with a high and very high HDI have high incidence and mortality rates. Because of this, the authors of the article suggested that health programs must be instituted in order to decrease the incidence and mortality rates of COVID-19 in these countries. 


\section{Methodology}

\section{Research Design}

The research design of the study is solely quantitative, with the data being sourced from the World Health Organization's Data Table of COVID-19 (World Health Organization, 2021), The World Bank's GDP (current US\$) (The World Bank, 2021), The World Bank's GDP per capita (current US\$) (The World Bank, 2021), and The World Bank's total population data (The World Bank, 2021). The data are collected from the latest release as of September 15, 2021 for the COVID-19 and population data. For the GDP and GDP per capita, they are accurate as of July 30, 2021.

The sample contains all of the countries that have data from both the World Health Organization and The World Bank, which allows for a wide economic range of countries being sampled. Most of these countries have experienced a year and a half of the pandemic. The number of COVID-19 cases goes from 0 cumulative cases from countries such as Kiribati and Micronesia to 40,804,998 cases from the United States last September 30, 2021 (World Health Organization, 2021). Population sizes are different too, with Nauru having the smallest population (10,764 people) and China having the largest population (1,397,715,000 people) last 2019 (The World Bank, 2021).

\section{Research Methods}

The incidence of COVID-19 can be defined as "the occurrence of new cases of a disease in a population over a specific period of time" (Lozier, 2020). It can be calculated using the following formula:

$$
\text { cases per } 100,000 \text { population }=\frac{\text { number of new cases of disease during specified period }}{\text { size of population during start of period }} \cdot 100000
$$

This formula allows researchers to compare and contrast the burden of COVID-19 across countries. Lozier also states that this will inform decisions regarding COVID-19. In order to calculate incidence rates for every country, the WHO's Data Table of COVID-19 entries for the total cumulative cases of COVID-19 will be divided by the population data for each country. The data for the population last 2019 will be collected from The World Bank's database.

The mortality rate can also be calculated using a similar formula to the incidence of COVID-19. The mortality rate is "a frequency of occurrence of death in a defined population during a specified interval" (U.S. Department of Health \& Human Services, 2011). Since the study focuses on a single cause, which is COVID-19, the measure for mortality will be a cause-specific death rate. The formula for the cause-specific death rate is the following:

$$
\text { cause-specific mortality rate }=\frac{\text { deaths occurring during a given time period }}{\text { size of the population anong which the deaths occurred }} \cdot 100000
$$

In order to calculate the mortality rate, the same database on COVID-19 as the incidence rate will be used, however, the column on the cumulative total of deaths will be used. The data for the population last 2019 will also be used in determining the cause-specific mortality rates of the different countries.

The economic metrics that the study will use are the gross domestic product and the gross domestic product per capita. Gross domestic product is a standardized economic metric of a country's performance on a global level, with the calculation involving the market value of all the goods and services that a country produces in a given timeframe (Mallet and Keen, 2012). According to the same article by Mallet and Keen, the GDP can be calculated using the following formula: 


$$
\mathrm{GDP}=\text { private consumption }+ \text { gross investment }+ \text { government spending }+ \text { exports }- \text { imports }
$$

The data set that will be used for the GDP is from The World Bank, which already calculated the metric for all of the countries. In addition to the GDP, this study will also analyze GDP per capita, which helps in analyzing why GDP grows (OECD, 2013). The GDP per capita data per country will be taken from The World Bank's database of GDP per capita. This metric is calculated by the formula below (Greenslaw and Shapiro, 2017):

$$
\text { GDP per capita }=\frac{\text { GDP }}{\text { population }}
$$

The data will be cleaned through Microsoft Excel and will be further analyzed through JASP software.

\section{Statistical Methods}

For statistical analysis, the incidence, mortality rates, GDP, and GDP per capita will be first tested for normality. Since the sample size of the data is greater than 50, the Kolmogorov-Smirnov test should be used (Mishra et al., 2019). If factors that are analyzed at a given time are normal, Pearson's product-moment correlation coefficient should be used (Mukaka, 2012). However, if one of the factors that are analyzed is not normal, Spearman's rank correlation coefficient should be used. Correlational analysis should be used in order to see if there is a relationship between these variables and if that relationship is significant. The pairings of the variables are shown below:

These calculations will be calculated with (1) all of the countries in the sample and (2) stratifying the different countries based on their income groups, which is classified by the World Bank. The countries are classified into four income levels based on their GNI per capita, which is defined as the GDP and the "net receipts from abroad of compensation of employees, property income and net taxes less subsidies on production" added together divided by the population of the country (OECD, 2020). These classifications are taken from the 2019 World Bank Country and Lending Groups (The World Bank, 2020), as the effects of COVID-19 are not yet felt when these classifications are made.

\section{Ethical Considerations}

This study shall observe the ethical standards throughout the research process. Since the data collected are from publicly available databases from reputable organizations, data quality is ensured. The privacy and anonymity of a person are important in conducting research dealing with data concerning humans (Allen, 2017). Because of this, there is no identifying information that could identify the people with COVID-19 from the different countries from the WHO databases, which ensures the anonymity and privacy of people with COVID-19. Lastly, there is no information that can pinpoint a person's social status in the databases of The World Bank's database of GDP, GDP per Capita, and population.

\section{Results}

Using the formula for the incidence and mortality rates mentioned above, these parameters are calculated through Microsoft Excel. The whole data set is then tested for normality in order to determine what type of correlation test would be used for the dataset. As the results show from Table 2, the data is not normally distributed because $\mathrm{p}<.05$.

Because of the results shown in Table 2, the correlation test that should be used is Spearman's rank correlation coefficient test. The results that are calculated are shown in Table 3. 
All of the correlations are statistically significant, with $\mathrm{p}<.001$. As the data shows, the correlation between the GDP and the incidence and mortality rates are weak positive, with a value of $\mathrm{r}_{\mathrm{s}}=.295$ and $\mathrm{r}_{\mathrm{s}}=.346$, respectively, whereas the correlation between the GDP per capita and the mortality rate is moderate positive, with $\mathrm{r}_{\mathrm{s}}=.521$. It is notable that the correlation between the GDP per capita and the incidence rate is strong positive, with $\mathrm{r}_{\mathrm{s}}=.656$.

In order to get a closer look at what is happening at different economic levels, the different countries are stratified according to their income levels. With this in mind, the results for low-income countries that have a GNI per capita of less than or equal to 1,035 US\$ are shown in Table 4. It is notable that there are no significant correlations between the four pairs.

The results from low-middle income countries, countries that have a GNI per capita between 1,036 US\$ 4,045 US\$, are shown in Table 5. The correlation between the GDP and the incidence and mortality rates of the low-middle income countries is not significant. However, the correlation between the GDP per capita of the incidence $\left(\mathrm{r}_{\mathrm{s}}=.362, \mathrm{p}=.011\right)$ and mortality rates $\left(\mathrm{r}_{\mathrm{s}}=.348, \mathrm{p}=.014\right)$ are statistically significant, with the correlation being weak.

For the upper-middle-income countries, the results of the statistical analysis are in Table 6 . Upper middleincome countries have a GNI per capita of between 4,046 US\$ and 12,535 US\$. As with the case for low-income countries, there is no significant correlation between the four factors mentioned below.

High-income countries are countries that have a GNI per capita greater than 12,535 US\$. With this in mind, the results for these countries are shown in Table 7. As with the case for the low-income and upper-middleincome countries, the correlations are not statistically significant.

\section{Discussion}

The results show that the GDP per capita and the mortality rate have a correlation of moderate positive, which shows that there is a relationship between the two factors. The GDP per capita and the incidence rate's relationships are even stronger, being a strong positive correlation. However, when stratified into different economic levels, the correlation yielded insignificant results, with only low-middle countries' GDP per capita levels and incidence and mortality rates yielding significant results.

The results heavily contradict a previous study done associating the change in new COVID-19 cases in European countries (Pardhan and Drydakis, 2021). The study shows that a country's GDP per capita is associated with lower incidence rates. Even though the economic well-being of a country is important because of healthcare's need for funding, this study shows that there might be other factors that might be associated with incidence and mortality rates, such as vaccination rates (Chen, 2021) and social norms (Gelfand et al., 2021).

In the case of GDP, results from GDP per capita largely hold the same, except for the levels of correlation for all countries. The levels of correlation for both incidence and mortality rates are just weak positive, which suggests that its relationship is less close than the GDP per capita.

Another possible factor confounding the relationship between infection and mortality rates and the economic status of a country is the government response towards the pandemic. For example, the United States, a high-income country, has an incidence rate of 12384.51 people infected per 100,000 people, making it the country in $14^{\text {th }}$ place in its incidence rate and $25^{\text {th }}$ place in its mortality rate. This is caused by the delay of proper health interventions such as lockdowns and testing that should have taken place as soon as possible (Sepulveda et al., 2021). In the same report, they had found that the lack of effective national response to the pandemic is detrimental in bringing down the cases of COVID-19.

In addition to this, multiple countries in the low-income bracket, such as Niger, Yemen, and Chad are among 
the lowest in their incidence rates. Low-income countries such as Burundi, Burkina Faso, and Niger are also among the lowest in their mortality rates. This just shows to show that there are other things that countries could do in improving their pandemic response aside from just strengthening their economy.

These results must be considered when countries are finding ways on how to improve pandemic responses in the future. Countries must not only consider their economic growth, but also consider other factors that are outside the scope of the study, such as healthcare, education, and cultural and social norms.

The main limitation of the study is the number of factors that are analyzed throughout the study. As shown above, there could be multiple factors affecting the incidence and mortality rates of COVID-19, which makes it imperative to study other factors affecting the disease. This might explain the disappearance of the significance of the correlations when analyzing the correlations from a generalized standpoint to a stratified standpoint.

Further studies analyzing other factors that affect the incidence and mortality rates of COVID-19 globally and locally must be done in order to help governments and communities adapt to this current pandemic by improving the aspects that are the most associated with the decrease of COVID-19 incidence and mortality rates.

\section{Conclusion}

While the COVID-19 pandemic is impacting the world economy, it is not known the extent of the relationship between COVID-19 incidence and mortality rates of countries and their GDP and GDP per capita. Datasets from WHO and the World Bank have been used in order to collect the data in order to perform the analysis. By finding the correlation of COVID-19 incidence and mortality rates to GDP and GDP per capita of all of the countries, it has been found that there is a strong correlation between GDP per capita and incidence rate. Other significant relationships had been found in other correlation pairs in the generalized analysis. However, these relationships mostly go away when the data are stratified, which suggests that a confounding variable is involved within this relationship. Future research that isolates that variable will be helpful for governments in dealing with the current COVID-19 pandemic and preparing their infrastructures in future pandemics as well.

\section{References}

Ahmad, T., Haroon, H., Baig, M., Hui, J., 2020. Coronavirus Disease 2019 (COVID-19) Pandemic and Economic Impact. Pakistan Journal of Medical Sciences 36. https://doi.org/10.12669/pjms.36. CoVID19S4.2638

Allen, M., 2017. Confidentiality and Anonymity of Participants, in: The SAGE Encyclopedia of Communication Research Methods. SAGE Publications, Inc, 2455 Teller Road, Thousand Oaks California 91320. https://doi.org/10.4135/9781483381411.n86

Chen, Y.-T., 2021. The Effect of Vaccination Rates on the Infection of COVID-19 under the Vaccination Rate below the Herd Immunity Threshold. International Journal of Environmental Research and Public Health 18, 7491. https://doi.org/10.3390/ijerph18147491

Connor, J., Madhavan, S., Mokashi, M., Amanuel, H., Johnson, N.R., Pace, L.E., Bartz, D., 2020. Health risks and outcomes that disproportionately affect women during the Covid-19 pandemic: A review. Social Science \& Medicine 266, 113364. https://doi.org/10.1016/j. socscimed.2020.113364

Ergönül, O., Akyol, M., Tanrı̈ver, C., Tiemeier, H., Petersen, E., Petrosillo, N., Gönen, M., 2021. National case fatality rates of the COVID-19 pandemic. Clinical Microbiology and Infection 27, 118-124. https: //doi.org/10.1016/j.cmi.2020.09.024 
Gelfand, M.J., Jackson, J.C., Pan, X., Nau, D., Pieper, D., Denison, E., Dagher, M., Van Lange, P.A.M., Chiu, C.-Y., Wang, M., 2021. The relationship between cultural tightness-looseness and COVID-19 cases and deaths: a global analysis. The Lancet Planetary Health 5, e135-e144. https://doi.org/10.1016/S25425196(20) 30301-6

Goenka, A., Liu, L., 2020. Infectious diseases, human capital and economic growth. Economic Theory 70, 1-47. https://doi.org/10.1007/s00199-019-01214-7

Greenslaw, S., Shapiro, D., 2017. Comparing GDP among Countries, in: Principles of Economics. OpenStax.

König, M., Winkler, A., 2021. COVID-19: Lockdowns, Fatality Rates and GDP Growth. Intereconomics 56, 32-39. https://doi.org/10.1007/s10272-021-0948-y

Lozier, M., 2020. Introduction to CDC COVID-19 Trajectory Analysis.

Mallet, J., Keen, C., 2012. Does GDP measure growth in the economy or simply growth inthe money supply?.

Miladinov, G., 2020. Socioeconomic development and life expectancy relationship: evidence from the EU accession candidate countries. Genus 76, 2. https://doi.org/10.1186/s41118-019-0071-0

Mishra, P., Pandey, C.M., Singh, U., Gupta, A., Sahu, C., Keshri, A., 2019. Descriptive statistics and normality tests for statistical data. Annals of Cardiac Anaesthesia 22, 67. https://doi.org/10.4103/aca. ACA_157_18

Mou, J., 2020. Research on the Impact of COVID19 on Global Economy. IOP Conference Series: Earth and Environmental Science 546, 032043. https://doi.org/10.1088/1755-1315/546/3/032043

Mukaka, M.M., 2012. Statistics corner: A guide to appropriate use of correlation coefficient in medical research.. Malawi medical journal : the journal of Medical Association of Malawi 24, 69-71.

OECD, 2013. GDP per capita. https://doi.org/10.1787/na_glance-2013-5-en

OECD, 2020. Gross national income. OECD Data.

Ottolini, F.L., Buggio, L., Somigliana, E., Vercellini, P., 2016. The complex interface between economy and healthcare: An introductory overview for clinicians. European Journal of Internal Medicine 36, 1-6. https://doi.org/10.1016/j.ejim.2016.07.030

Pardhan, S., Drydakis, N., 2021. Associating the Change in New COVID-19 Cases to GDP per Capita in 38 European Countries in the First Wave of the Pandemic. Frontiers in Public Health 8. https://doi.org/ $10.3389 /$ f pubh .2020 .582140

Sepulveda, J., Feachem, N.S., Sanders, K., Barker, F., 2021. The United States' Response to COVID-19: A Case Study of the First Year. University of San Francisco, Institute for Global Health Studies.

Shahbazi, F., Khazaei, S., 2020. Socio-economic inequality in global incidence and mortality rates from coronavirus disease 2019: an ecological study. New Microbes and New Infections 38, 100762. https: //doi.org/10.1016/j.nmni.2020.100762

Sharma, G.D., Mahendru, M., 2020. Lives or livelihood: Insights from locked-down India due to COVID19. Social Sciences \& Humanities Open 2, 100036. https://doi.org/10.1016/j.ssaho.2020.100036

de Oliveira, R.P., Achcar, J.A., Nunes, A.A., 2020. Modeling the incidence and death rates of COVID-19 pandemic in different regions of the world. Epidemiologic Methods 9. https://doi .org/10.1515/em-20200017

Our World In Data, 2021. Share of people who received at least one dose of COVID-19 vaccine.

The World Bank, 2021. World Development Indicators. DataBank. 
The World Bank, 2021. Population, total.

The World Bank, 2020. World Bank Country and Lending Groups. The World Bank Data.

U.S. Department of Health \& Human Services, 2011. Section 3: Mortality Frequency Measures, 3rd ed, Principles of Epidemiology in Public Health Practice. Centers for Disease Control and Prevention.

United Nations Development Programme, 2020. Human Development Report 2020 - Technical notes.

World Health Organization, 2021. WHO Coronavirus (COVID-19) Dashboard. 


\section{Tables}

Table 1. Pairings of variables for correlational analysis.

\begin{tabular}{ll}
\hline Variable 1 & Variable 2 \\
\hline GDP & Incidence rate \\
GDP & Mortality rate \\
GDP per Capita & Incidence Rate \\
GDP per Capita & Mortality Rate \\
\hline
\end{tabular}

Table 2. Results of the Kolmogorov-Smirnov test.

\begin{tabular}{lcc}
\hline Parameter & Statistic & p \\
\hline GDP & $1.000^{* * *}$ & $<.001$ \\
GDP per Capita & $.255^{* * *}$ & $<.001$ \\
Population & $.398^{* * *}$ & $<.001$ \\
Incidence Rate & $.166^{* * *}$ & $<.001$ \\
Mortality Rate & $.200^{* * *}$ & $<.001$ \\
\hline
\end{tabular}

${ }^{*} \mathrm{p}<.05,{ }^{* *} \mathrm{p}<.01,{ }^{* * *} \mathrm{p}<.001$

Table 3. Correlations for parameters (all countries).

\begin{tabular}{|c|c|c|c|}
\hline & & Spearman's rho & $\mathbf{p}$ \\
\hline GDP & - Incidence Rate & $.295^{* * *}$ & $<.001$ \\
\hline GDP & - Mortality Rate & $.346^{* * *}$ & $<.001$ \\
\hline GDP per Capita & - Incidence Rate & $.656^{* * *}$ & $<.001$ \\
\hline GDP per Capita & - Mortality Rate & $.521^{* * *}$ & $<.001$ \\
\hline
\end{tabular}

$* \mathrm{p}<.05,{ }^{* *} \mathrm{p}<.01,{ }^{* * *} \mathrm{p}<.001$

Table 4. Correlations for parameters (low-income countries).

\begin{tabular}{|c|c|c|c|}
\hline & & Spearman's rho & $\mathbf{p}$ \\
\hline GDP & - $\quad$ Incidence Rate & -.167 & .434 \\
\hline GDP & - Mortality Rate & .051 & .812 \\
\hline GDP per Capita & - Incidence Rate & 143 & .505 \\
\hline GDP per Capita & - Mortality Rate & .07 & .743 \\
\hline
\end{tabular}

Table 5. Correlations for parameters (low-middle income countries).

\begin{tabular}{|c|c|c|c|}
\hline & & Spearman's rho & $\mathrm{p}$ \\
\hline GDP & - Incidence Rate & .019 & .896 \\
\hline GDP & - Mortality Rate & .127 & .385 \\
\hline GDP per Capita & - Incidence Rate & $.362^{*}$ & .011 \\
\hline GDP per Capita & - Mortality Rate & $.348^{*}$ & .014 \\
\hline
\end{tabular}

${ }^{*} \mathrm{p}<.05,{ }^{* *} \mathrm{p}<.01,{ }^{* * *} \mathrm{p}<.001$

Table 6. Correlations for parameters (upper-middle income countries).

\begin{tabular}{|c|c|c|c|}
\hline & & Spearman's rho & p \\
\hline GDP & - Incidence Rate & .107 & .457 \\
\hline GDP & - Mortality Rate & .272 & .056 \\
\hline GDP per Capita & - Incidence Rate & .112 & .437 \\
\hline GDP per Capita & - Mortality Rate & -.001 & .993 \\
\hline
\end{tabular}

$* \mathrm{p}<.05,{ }^{* *} \mathrm{p}<.01,{ }^{* * *} \mathrm{p}<.001$ 
Table 7. Correlations for parameters (high income countries).

\begin{tabular}{|c|c|c|c|}
\hline & & Spearman's rho & $\mathbf{p}$ \\
\hline GDP & Incidence Rate & .147 & .295 \\
\hline GDP & - Mortality Rate & .172 & .218 \\
\hline GDP per Capita & - Incidence Rate & -.007 & .958 \\
\hline GDP per Capita & - Mortality Rate & -.215 & .122 \\
\hline
\end{tabular}

